\title{
Increased mortality in COPD among construction workers exposed to inorganic dust
}

\section{To the Editor:}

I read with interest the recent publication by BERGDAHL et al. [1] on the increased mortality in chronic obstructive pulmonary disease (COPD) among construction workers exposed to inorganic dust. Within this publication, the authors stated that their "results corroborate those from previous studies, indicating an increased risk for COPD among workers exposed to dust, such as asbestos, man-made mineral fibres, mineral dust and concrete dust".

The basis cited by BERGDAHL et al. [1] for including fibre glass in the previous statement appears to be the article by SIXT et al. [2]. The authors citing this article state that "increased elastic recoil pressure among workers exposed to man-made mineral fibres has also been described". It is unfortunate that BERGDAHL et al. [1] did not include the full citation from SIXT et al. [2].

The exact quotation from SiXT et al. [2] is as follows: "In summary, in a small number of subjects exposed to fiber glass, we found slightly increased elastic recoil but no evidence of small airway dysfunction, restrictive ventilatory impairment, or airway obstruction. It is not possible from this study to generalize as to the hazard of handling fiber glass, but it may serve to indicate a need for further studies on the effect of fiber glass inhalation on lung function."

It should be noted, in addition, that further studies have not reported any relationship of fibre glass exposure to lung function impairment.

In the International Agency for Research on Cancer (IARC) monograph [3], which examined the classification of man-made mineral fibres, the IARC working group stated, in review of the SIXT et al. [2] study, that "no evidence of small airways dysfunction or resting ventilatory impairment was found in six nonsmoking sheet-metal workers who had been exposed to glass fibre".

In addition, BERGDAHL et al. [1] include a study by ENGHOLM et al. [4] in their reference list, without discussing any details of this study in their text. In the IARC monograph [5], which re-examined the classification of man-made mineral fibres, the IARC working group reported the following, concerning the study by ENGHOLM et al. [4]:

"A study on a cohort of 135,037 male construction workers in Sweden reported in 1987 and evaluated by the previous Working Group (IARC, 1988) has not been updated (Engholm et al., 1987). In a nested case-control study, the relationship between lung cancer in 424 workers and their exposure to MMVFs and to asbestos was examined. After adjustment for smoking habits and population density in the area of residence, an odds ratio of 1.21 (95\% CI, 0.60-2.47) was reported for exposure to MMVFs (adjusted for exposure to asbestos). Twenty-three cases of pleural cancer were observed among the cohort (SIR, 2.13; 95\% CI, 1.35-3.20). (The Working Group noted that misclassification of exposure to asbestos and the difficulty in differentiating exposure to asbestos from exposure to MMVFs may have resulted in residual confounding.)"

It should be noted that this study was not considered as sufficient in establishing the final classification of fibre glass as category 3 by the IARC working group [5].

Thus, a thorough review of the two references cited by BERGDAHL et al. [1], with reference to fibre glass, indicates that there is no scientific basis for including fibre glass in their discussion of increased mortality in chronic obstructive pulmonary disease among construction workers exposed to inorganic dust.

\section{D.M. Bernstein}

$40 \mathrm{ch}$. de la Petite-Boissière, Geneva, Switzerland.

\section{References}

1. Bergdahl IA, Toren K, Eriksson K, et al. Increased mortality in COPD among construction workers exposed to inorganic dust. Eur Respir J 2004; 23: 402-406.

2. Sixt R, Bake B, Abrahamsson G, Thiringer G. Lung function of sheet metal workers exposed to fibre glass. Scand $J$ Work Environ Health 1983; 9: 9-14.

3. IARC Monograph Vol. 43. Man-made mineral fibres and radon. Lyon, IARC Press, 1987.

4. Engholm G, Englund A, Fletcher AC, Hallin N. Respiratory cancer incidence in Swedish construction workers exposed to man-made mineral fibres and asbestos. Ann Occup Hyg 1987; 31: $663-675$.

5. IARC Monograph Vol. 81. Man-made vitreous fibres. Lyon, IARC Press, 2001.

\section{From the authors:}

We are grateful for the valuable comments by D.M. Bernstein. We fully agree with him that the papers we cited do not corroborate our findings. The cited papers do not support our observation about exposure to inorganic dust, including fibre glass, and increased mortality to chronic obstructive pulmonary disease in a convincing way. However, the important conclusion from our paper is that exposure to inorganic dust, comprising fibre glass, should be kept to a minimum in the workplace.

Mostly as a result of power considerations, we merged several kinds of inorganic dust, fibre glass, silica dust, asbestos, concrete and cement to one entity. However, if we look at the separate dust entities, exposure to fibre glass was associated with increased chronic obstructive pulmonary disease mortality. The relative risk was 1.41 with a $95 \%$ confidence interval ranging 1.09-1.82. The risk estimate was adjusted for age and smoking.

I. Bergdahl*, K. Torén", , T. Nillson*, K. Eriksson*, U. Hedlund ${ }^{+}$, R. Flodin ${ }^{\S}$, B. Järvholm*

*Occupational Medicine, Dept of Clinical Medicine and Public Health, Umeå University, Umeå, Depts of ${ }^{\#}$ Occupational and Environmental Medicine, and "Allergology, Sahlgrenska University Hospital, Göteborg, ${ }^{+}$Dept of Occupational and Environmental Medicine, Sundsvall Hospital, Sundsvall, and ${ }^{\S}$ AB Previa, Kista, Sweden. 